\title{
Diacronie
}

Studi di Storia Contemporanea

$N^{\circ} 19,3 \mid 2014$

Miscellaneo

\section{Identitades vernáculas, propaganda subliminal y sentimiento nacionalista}

La "Sección retrospectiva" de la exposición internacional de Barcelona de 1923 o la feria de las vanidades del meuble español

Juan Antonio Sánchez López y Antonio Rafael Fernández Paradas

\section{(2) OpenEdition \\ Journals}

\section{Edición electrónica}

URL: http://journals.openedition.org/diacronie/1566

DOI: $10.4000 /$ diacronie. 1566

ISSN: 2038-0925

Editor

Association culturelle Diacronie

Referencia electrónica

Juan Antonio Sánchez López y Antonio Rafael Fernández Paradas, « Identitades vernáculas,

propaganda subliminal y sentimiento nacionalista », Diacronie [En línea], N 19, 3 | 2014, documento 2 , Puesto en línea el 01 septiembre 2014, consultado el 21 abril 2019. URL : http://

journals.openedition.org/diacronie/1566; DOI : 10.4000/diacronie.1566 


\title{
Diacronie
}

\section{Identitades vernáculas, propaganda subliminal y sentimiento nacionalista}

\section{La "Sección retrospectiva" de la exposición internacional de Barcelona de 1923 o la feria de las vanidades del meuble español}

\author{
Juan Antonio SÁNCHEZ LÓPEZ, Antonio Rafael FERNÁNDEZ PARADAS *
}

La Exposición Internacional del Mueble y Decoración de Interiores, celebrada en Barcelona en 1923, no solo presentaba los muebles como testimonio documental de los usos, modos y maneras y de las formas de vida. La muestra también sirvió a los organizadores para reconstruir la Historia de España y Cataluña desde la Edad Media al siglo XVIII través de las ocho "habitaciones" que integraban la Sección Retrospectiva. A través de estas escenografías percibimos los valores identitarios y antropológicos del mueble como "producto" cultural de las sociedades, haciendo gala de un sentido teatral y escenográfico que contrasta con la visión arqueológica y rigurosamente "científica" del pasado. Desde la perspectiva catalana, el significado de la Exposición se revistió de un significado "nacionalista" ligado a lo español que fue secundado por los organizadores y denostado por sus detractores, más cercanos al independentismo secesionista.

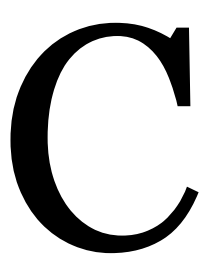

on independencia de cuál sea su patria u origen, y desde su más pura dimensión objetual, el mueble es susceptible de ser considerado desde diferentes puntos de vista. Ya sea como obra de arte, producto cultural, indicador industrial, demostración artesana, referente económico o testimonio emblemático -y, por extensión, elocuentemente ilustrativo de 
la posición social de su poseedor- el mueble también es capaz de desvelarnos otra sorprendente faceta como aquella otra que tendería a considerarlo y, a la postre, visualizarlo en calidad de "signo" identitario de comunidades y territorios. Y qué duda cabe que una exposición, y máxime si ésta adquiere el rango de "internacional", constituye el mejor escaparate para cuanto pretenda transmitirse a través del mismo.

Semejantes consideraciones nos instan a reconocer en un mueble, y ante todo, un ente corpóreo que ocupa un lugar físico en el espacio, bastante considerable por lo general. De ello se infiere que los muebles aparezcan como solución recurrente a la hora de llenar "espacios" en exposiciones temporales. Desde esta perspectiva, los muebles son también obras muy agradecidas a la hora de construir el discurso de una muestra, por ser piezas voluminosas, de considerables dimensiones y muy socorridas escenográficamente hablando. En este sentido, toda exposición que pretenda erigirse en testigo vivo ya sea de aspectos sociales, históricos o artísticos concretos, de memoria visual de una época y/o en testimonio directo de una personalidad no podrá prescindir de la inestimable colaboración de aquellos muebles que ayudarán a contextualizar oportunamente los hechos, acciones o acontecimientos descritos y/o a crear ambientaciones apropiadas en torno a la recreación de la historia de las personas.

No obstante, no son precisamente de esta índole las exposiciones que aquí nos interesan. Más bien nos atraen aquellas otras que, a lo largo del pasado siglo XX, han contado entre sus fondos expositivos con diferentes tipos de mobiliario que han sido, por algún motivo, parte inevitable y obligatoria en diferentes exposiciones internacionales desarrolladas en el contexto geográfico español, por no hablar de aquellas donde el mueble ha marcado de modo indeleble el carácter monográfico y la repercusión social de tales eventos.

La Exposición Internacional del Mueble y Decoración de Interiores, celebrada en Barcelona en 1923 ilustra como pocas la dimensión social poliédrica de esta suerte de iniciativas en la Historia Contemporánea. En ella, el mueble no sólo aparecía como testimonio documental de los usos, modos y maneras, de las formas de vida y de las aspiraciones sociales de quienes lo poseen y hacen ostentación y uso visible del mismo, de cara a su propia afirmación "de clase”. También la muestra sirvió a los organizadores de "instrumento" de debate y aún de escaparate reivindicativo al pretenderse poner en valor los innegables y ya referidos valores identitarios y antropológicos del mueble como "producto" cultural de las sociedades, para trazar subliminalmente un imaginario itinerario propagandístico desde el catalanismo nacionalista/secesionista al vernáculo/españolista. 


\section{Las exposiciones de muebles en España en el primer tercio del siglo XX. Sus antecedentes desde la historiografía}

El estudio de las exposiciones en España es una de tantas cuestiones olvidadas por la historiografía española; por lo demás, algo difícil de entender por cuanto su origen se encuentra intrínsecamente ligado al de la propia Historia del Mueble en España ${ }^{1}$. De hecho, cuando en España se comenzaron a tener en cuenta nuestros muebles - lo cual sucedería, justo es decir, allá por la década de los setenta del Ochocientos - hubo que mirar obligatoriamente a Londres, y a lo que allí se estaba haciendo de la mano de Juan Facundo Riaño. No en balde, el camino hacia las exposiciones temporales de muebles españoles discurriría casi en paralelo a los primeros trabajos que el referido autor comenzaba a editar para el South Kensington Museum, como consecuencia de la reorganización de las colecciones de arte español custodiadas por dicho centro² ${ }^{2}$

No menos significativo para nuestro objeto de análisis se antoja el año 1879. En ese mismo año, Francisco Miquel y Badía publicaba un libro singular bajo un título no menos pintoresco y singular: Muebles y tapices. Segunda serie de cartas a una señorita sobre la habitación ${ }^{3}$. Al tiempo, se celebraba en París una exposición sobre las Artes Decorativas Españolas de la Edad Media al Renacimiento cuyos organizadores tuvieron a bien editar un pequeño catálogo de 88 páginas, altamente significativo de la importancia conferida al tema. Más que el opúsculo en sí, nos interesa la exposición tal cual por tratarse de una de las primeras muestras que recogen muebles españoles, cuyos textos están en relación con las pautas metodológicas apuntadas en las reseñadas obras de Juan Facundo Riaño, lo cual también nos sirve para constatar la rápida difusión de las mismas en otros entornos diferentes al británico.

De esta manera, las exposiciones dedicadas exclusivamente a muebles no podían tardar en llegar. La primera de ellas se inauguró en Madrid en 1912, a las cuales se añaden las dos que tuvieron lugar en Barcelona en 1923. La muestra madrileña se

\footnotetext{
${ }^{1}$ FERNÁNDEZ PARADAS, Antonio Rafael, Historiografía y Metodologías de la Historia del Mueble en España (1872-2011). Un Estado de la Cuestión, Tesis Doctoral en Historia del Arte, Universidad de Málaga, Málaga, a.a. 2011-2012.

${ }^{2}$ RIAÑO Y MONTERO, Juan Facundo, Essay of Spanish art, in ROBINSON, John Charles, Catalogue of the especial loan exhibition of Spanish and portuguese ornamental Art. South Kensington Museum, London, R. Clay and Taylor, 1881; RIANO, Juan Facundo, The industrial Arts in Spain, London, Chapman and Hall, 1879, pp. 108-125; ID., Classified and descriptive catalogue of the objects of Spanish production in the South Kensington Museum with an introduction by..., London, George E. Eyre and William Spottiswoode for H.M.S.O, 1872.

3 MIQUEL Y BADÍA, Francisco, Muebles y tapices. Segunda serie de cartas a una señorita sobre la habitación, Barcelona, Libreria de Juan y Antonio Bastinos, 1879.
} 
celebró bajo la expresiva denominación de Álbum de la Exposición de mobiliario español de los siglos XV y XVI y la primera mitad del siglo XVII, cuyo catálogo tuvo una segunda edición en 1918, centrado preferentemente en los muebles tardomedievales y renacentistas. La ostensible preeminencia del aparato gráfico sobre la información escrita que informa la carta de presentación de dicha publicación (en realidad y más bien un álbum - como él mismo se intitula - que un catálogo como tal en sentido estricto) ha querido atribuirse a la escasa disponibilidad de información que, hasta ese momento, se tenía sobre cuestiones relativas al mobiliario ${ }^{4}$. En ese mismo año de 1912, y al hilo de lo que debió ser, sin duda, un acontecimiento de máxima actualidad, la Sociedad Española de Amigos del Arte publicó un artículo-reseña dedicado a la misma unido a un inventario, textos ambos que fueron incorporados a la reedición de dicho Álbum en 1918 .

Contemplado desde la historiografía, el caso barcelonés merece una atención especial a raíz de lo que supuso para la ciudad la celebración de la Exposición Universal de 1888. Desde la primera Exposición Universal celebrada en Londres en 1851, sobradamente conocida es la incidencia extraordinaria de estos eventos en el contexto de los países y ciudades anfitrionas, no sólo por lo que supusieron de escaparate para las mismas a la hora de fomentar el renombre mundial con el consecuente flujo de visitantes, de acicate para grandes inversiones y transformaciones urbanísticas, de oportunidad inmejorable para comercializar y dar a conocer los productos industriales y culturales o de inequívoco canto a la modernidad a la hora de difundir entre el gran público los grandes avances tecnológicos de la era industrial que estaban revolucionando y cambiando literalmente el mundo. Desde una perspectiva paralela, también las Exposiciones fueron igualmente relevantes por lo que las mismas tuvieron de reencuentro con el pasado histórico, con las tradiciones locales, con las idiosincrasias comunitarias; en definitiva, con la puesta en valor de la singularidad y sentimiento nacionalista de los pueblos en el contexto de un mundo que, quizás sin saberlo todavía, comenzaba en el siglo XX el frenético camino hacia la globalización.

Para nuestro tema, el annus aureus de Barcelona no sería otro que el de 1923 por lo decisivo que resultara para el conocimiento de la decoración de los interiores catalanes y, por añadidura, para la propia Historia del Mueble Español. Para empezar se editó el libro de Jeroni Martorell Interiors. Estructures autentiques d'habitacions del segle

\footnotetext{
4 MOYA VALGAÑÓN, José Gabriel, Un siglo de Historiografía del mueble español, in Mueble Español. Estrado y Dormitorio, Madrid, Comunidad de Madrid, 1990, pp. 11-22.

5 ALMENAS, Conde de, «La exposición de antiguo mobiliario español», in Arte Español, I, 2/1912, pp. 50-54; VALVERDE, Marqués de, «Catálogo de la Exposición de mobiliario español de los siglos XV y XVI y primera mitad del siglo XVII», in Arte Español, I, 2/1912, pp. 54-57.
} 
$X I I I$ al $X I X^{6}$ y, por supuesto, según referimos, tuvieron lugar dos exposiciones sobre estas cuestiones: la Exposición Internacional del Mueble y Decoración de Interiores y su correspondiente "antídoto" L'amoblement $i$ els atuells de la casa antiga a Catalunya. En principio, ambas muestras debieran haber sido complementarias, pero terminaron siendo todo lo contrario: enemigas irreconciliables $y$ eventos representativos de ópticas muy diferentes a la hora de plantear, diseñar, organizar y planificar una magna exposición. Por esta razón, no puede sorprendernos que ambas levantaran pasiones y críticas por igual y contasen con tantos defensores como detractores. Es obvio que la diferente percepción "nacionalista" inherente y subyacente en uno (de signo españolista) y otro caso (de signo catalanista) constituyen las claves de la controversia.

\section{La "Sección retrospectiva" de la exposición internacional del mueble y decoración de interiores: la visión del pasado como enseñanza y poesia}

No podría comprenderse en su plenitud la trascendencia de la Exposición Internacional de 1923 sin considerarla la consecuencia "lógica" de un proceso que nos desvela la alta estimación que el mueble venía disfrutando en Cataluña como un elemento que, no sólo nos habla de la clase social a la que iba destinado, sino que viene definido como un elemento económico que, hasta bien entrado el siglo XIX, marcaba incluso la "libertad" de quien lo posee7. Asimismo, debemos considerar otras cuestiones no menos contundentes sobre el particular como el hecho mismo de que el mueble catalán estuviese sujeto, desde la Edad Media, a un procedimiento legislativo. Ello justifica la realidad jurídica misma de que fuese objeto de una especial protección y conservación, según avala una numerosa documentación y, por supuesto, un nutrido catálogo de piezas. No menos contundente se antoja la renovada situación vivida por la tradición ebanista catalana desde finales del Ochocientos, cuando sus creaciones entran en los "limbos" de la Historia del Arte con el Modernismo y se editan los textos de Lluís Rigalt i Farriols que pretenden eliminar la línea que separa tradición y mecanización,

\footnotetext{
${ }^{6}$ MARTORELL, Jeroni, Interiors. Estructures autentiques d'habitacions del segle XIII al XIX. Exposició de Barcelona. Repertori iconogràfic, Barcelona, Seix i Barrall, 1923.

7 FERNÁNDEZ PARADAS, Antonio Rafael, «La búsqueda de una identidad: Cataluña y el mueble como herramienta nacionalista. Exégesis de una historiografía», in Baetica. Estudios de Arte, Geografía e Historia, 34, 2012, pp. 437-449.
} 
entre artesanía e industria ${ }^{8}$. Asimismo, en 1913 arranca la historiografía del mueble catalán preparando el terreno, desde los años veinte, a las exposiciones sobre mobiliario catalán que terminarán convirtiéndose en una constante en la vida social de esta comunidad histórica al imbuirse de un marcado carácter nacionalista9.

Si de las líneas anteriores, se infiere cómo el mueble define un sistema económico, social, legislativo y cultural propio del área catalana, cabe responsabilizar a eventos del calibre de la Exposición Internacional del Mueble de 1923 de haber servido de estímulo a la historiografía a la hora de multiplicar, a lo largo del siglo XX y lo que llevamos del XXI, los estudios y las metodologías de aproximación al mueble catalán y sus circunstancias. Semejante situación ha venido dándose en relación casi directamente proporcional al número de investigadores e historiadores del Arte que han venido apreciando la calidad de los muebles, al unísono de la rentabilidad y aprovechamiento de su puesta en valor que, al unísono de tales avances historiográficos, han venido protagonizando los agentes dedicados a su comercio.

La Exposición de 1923 es consecuencia del clima generado en Europa por la Exposición Universal de París de 1900 que generó la consagración del Art Nouveau como un registro estético ligado a una renovación formal sin precedentes en la concepción de los objetos suntuarios, cuya consecuencia directa sería la Exposición de Artes Decorativas Modernas celebrada en Turín en 1902. La ausencia española de tales eventos y el afán por impulsar las Artes Decorativas motivaron la fundación en el ámbito catalán, en 1903, del FAD (Foment de les Arts Decoratives), cuya puesta de largo vendría precisamente de la mano del evento protagonista de este trabajo y cuya exitosa trayectoria en pro de la consecución de sus fines, truncada por el estallido de la Guerra Civil, perduraría hasta $1936^{10}$.

El comité organizador de la muestra, presidido por el propio Alcalde de Barcelona el Marqués de Alella, estaba formado por destacados protagonistas de la vida social y cultural catalana como Lluís Nicolau d'Olwer, Marià Fuster, Antoni Valls, Joan Busquets, Casimir Giralt, Pere Reig y Pere Bohigas, a quienes se sumaban dos

\footnotetext{
8 RIGALT i FARRIOLS, Lluís, Álbum gráfico de las artes y los oficios, Barcelona, Jaime Jepus, 1884; ID., Álbum enciclopédico-pintoresco de las artes industriales, Barcelona, Litografía de La Unión de Francisco Campañá, 1857.

9 FERNÁNDEZ PARADAS, Antonio Rafael, «Bibliografía de la Historia del Mueble español (1872-2012)», in ASRI. Arte y Sociedad. Revista Investigación, 3, 2013, URL:

$<$ http://asri.eumed.net/3/bibliografia-historia-mueble-espanol.html > [consultado el 13 septiembre de 2014].

10 SALA GARCÍA, Teresa M., Catálogos y Guías de Exposiciones Internacionales. Dos ejemplos significativos: el de las "Artes Decorativas Modernas" de Turín (1902) y el del "Moble i Decoració d'Interiors" de Barcelona (1923), in CANTARELLAS CAMPS, Catalina, Modelos, intercambios y recepción artística. De las rutas marítimas a la navegación en red, Palma de Mallorca, Universitat Illes Balears, 2008, pp. 991-999.
} 
personalidades de excepción: el arquitecto y Rector de l'Escola d'Arts i Oficis i Belles Arts, Manuel Vega, y el decorador y presidente del FAD, Santiago Marco. Uno y otro constituyen figuras claves del panorama artístico del momento, en cuanto a sendos elementos responsables, y a la postre artífices, de la reivindicación nacionalista de la que terminaría impregnándose el acontecimiento. De hecho, y ya en su momento, el primero había protagonizado un lastimero llamamiento a la conciencia colectiva y la opinión pública ante la referida ausencia española de la Exposición de Turín. Su afligido llamamiento daría resultado de inmediato, habida cuenta de que las fuerzas vivas competentes se movilizaban y gestionaban las diligencias que conducirían a la institución del FAD, del que el segundo se convertiría en uno de sus grandes impulsores desde su llegada a la presidencia de la entidad, en $1920^{11}$.

En consecuencia, la Exposición de 1923 se antoja decisiva al menos por cinco aspectos fundamentales para la Historia del Mueble y la visión del mismo: la conciliación del ámbito profesional con la vertiente pedagógica y educativa encauzada al conocimiento y los aspectos técnicos de su realidad material, el objetivo de aunar la competencia con la competitividad en el sector, promover la internacionalización y difusión de los industriales y diseñadores catalanes, apostar sin ambages por la modernidad como el parámetro que refrendase la funcionalidad y las garantías de confort brindadas por los productos ofrecidos y, finalmente, la consagración del mobiliario histórico como referente de prestigio que refrenda el culto al pasado como sinónimo del esplendor y el orgullo nacionales.

No en balde, la organización e inauguración del evento vinieron casi a coincidir con el inicio de la Dictadura del General Miguel Primo de Rivera, caracterizada por un nacionalismo español autoritario y beligerante que, entre otros aspectos, pretendía poner coto a la «descarada propaganda separatista», según reza el manifiesto dirigido por el propio General al país y al ejército a raíz del golpe de Estado del 13 de septiembre de 1923. De ahí que el diario $A B C$, entre otros sectores interesados en la exaltación de los valores patrios españoles en detrimento de los nacionalismos regionales (catalanes en particular), mostrase un inusitado interés en la Exposición. No sólo creando gran expectación en torno a ella desde que el proyecto comenzase a tomar forma, sino haciéndolo suyo en toda regla al considerarlo una «muestra de la riqueza productora que siempre imperó en el mobiliario nacional» ${ }^{12} \mathrm{y}$ en connivencia con los objetivos perseguidos por la Exposición Internacional de Industrias Eléctricas «de la que la

\footnotetext{
${ }^{11}$ Ibidem, p. 996.

${ }^{12}$ GARRO, Enrique, «La Exposición Internacional del Mueble y Decoración de Interiores», in $A B C, 14$ febrero 1923.
} 
Exposición del Mueble será un prólogo consolador para los que amamos a España y sentimos orgullo de su poderío de producción»13.

Enclavada en el Parque de Montjuich donde «comenzaron las primeras romerías de los hombres de industria y de inteligencia, plantando entre los jardines sus ferias rutilantes»14, la Exposición se vertebró en varias secciones dedicadas al mueble moderno, a las habitaciones modernas, a las artes decorativas y productos industriales para el ajuar de una casa y una de carácter específicamente francés, sin olvidar otras dedicadas a la "Casa Humilde", a las "Exhibiciones Técnicas" y, finalmente, a la visión retrospectiva o histórica ${ }^{15}$. Aunque nos centraremos en esta última no podemos pasar de largo las intenciones democratizadoras de las secciones de la "Casa Humilde" y "Exhibiciones Técnicas" en el sentido de poner al alcance de todos los segmentos sociales la posibilidad de embellecer el hogar con el concurso del mueble. Al hacer gala de esta actitud, los organizadores ramificaban las aspiraciones de crecimiento del mercado del mueble en términos de oferta y demanda, sin dejar de contemplar en el mismo un sector profesional interesante con amplias posibilidades de crecimiento y diversificación en la vertiente operativa, técnica, sectorial, estética y decorativa:

[...] facilitar a las familias obreras o de modesta condición económica el embellecimiento del hogar [...] [respondiendo] al deseo del Comité Ejecutivo de acompañar las exhibiciones industriales de todas aquellas otras manifestaciones relativas al amueblamiento y decorado de la vivienda humana, cuyo conocimiento puede contribuir a la perfección y al desarrollo de las diversas ramas de esta actividad industrial, y a juzgar por los proyectos y detalles que obran en las oficinas presentar interesantes orientaciones para impulsar el embellecimiento y el confort del interior de la casa, sin que ello exija grandes dispendios.

[...] Además constituirá, sin duda, un aspecto pintoresco y altamente original, así para posibles derivaciones de la industria del mueble como para la evolución de las artes decorativas ${ }^{16}$.

En principio, la justificación de la Sección Retrospectiva vino marcada por un argumento de lógica que, hasta cierto punto, indujo a los responsables de la muestra a considerar su presencia en el evento una "necesidad", habida cuenta de que en

\footnotetext{
13 Ibidem.

14 Exposición Internacional del Mueble y Decoración de Interiores. Guía del Visitante, Barcelona, Ediciones de Lujo Anglada-Albert, 1923.

15 Exposición Internacional del Mueble y Decoración de Interiores. Catálogo, Barcelona, A. López Llausàs, 1923.

16 GARRO, Enrique, op. cit.
} 
[...] una exhibición del mueble y de conjunto de interiores debía precisamente haber una sección destinada al mueble antiguo y en particular a una serie de estands que reprodujeran salas de los diversos estilos que han dominado España, a lo cual ha atendido el Comité de este certamen, utilizando el archivo del Repertorio Iconográfico de España, que mandó hacer la Junta de la futura Exposición Internacional ${ }^{17}$.

Aunque, inicialmente, la Sección Retrospectiva pretendía venir marcada por los acentos más puramente pedagógicos, en cuanto presuntamente ilustrativos e ilustradores de la secuencia cronológica del mueble desde 1260 a 1860 aproximadamente, bien pronto se vio sugestionada por un declarado talante conservador que propugnaba un reencuentro - en realidad «reinvención» - con el pasado a través de una secuencia de recreaciones escenográficas donde lo pintoresco, lo teatral y lo castizo terminan imperando por encima del rigor histórico, científico, antropológico, arqueológico y sobre cualquier otro criterio metodológico, por más que los organizadores mostrasen el empeño de ir «examinando los proyectos y tomando acuerdos importantes encaminados a asegurar la máxima fidelidad histórica de las instalaciones ${ }^{18}$.

De hecho, así lo reconoce el texto que sirve de entradilla a la Guía del Visitante de la Sección Retrospectiva (fig. 1), donde sin fisuras y de manera explícita, se sugieren y anticipan las potencialidades «embaucadoras» de tales escenografías que invitan a leerlas y «comprenderlas» más bien como auténticas paráfrasis - y, como tales, subjetivas y arbitrarias - que como reconstrucciones fidedignas de los grandes momentos de la trayectoria del mobiliario:

La visión del pasado que la Sección Retrospectiva nos ofrece es algo así como una enseñanza y una poesía: enseñanza en cuanto revela el proceso de una industria y del arte; poesía en cuanto evoca los encantos de las edades pretéritas que son matices delicados de las páginas de la Historia.

\footnotetext{
${ }^{17}$ Exposición Internacional del Mueble y Decoración de Interiores. Sección Retrospectiva. Guía del Visitante, Barcelona, A. López Llausás, 1923.

18 GARRO, Enrique, op. cit.
} 
Barcelona, que con su Exposición del Mueble pretende impulsar las iniciativas industriales del futuro, rinde homenaje de respeto en la Sección Retrospectiva a nuestro grandioso pasado ${ }^{19}$.

Fig. 1. Portada de la Guía del Visitante. Exposición Internacional del Mueble. Barcelona 1923.

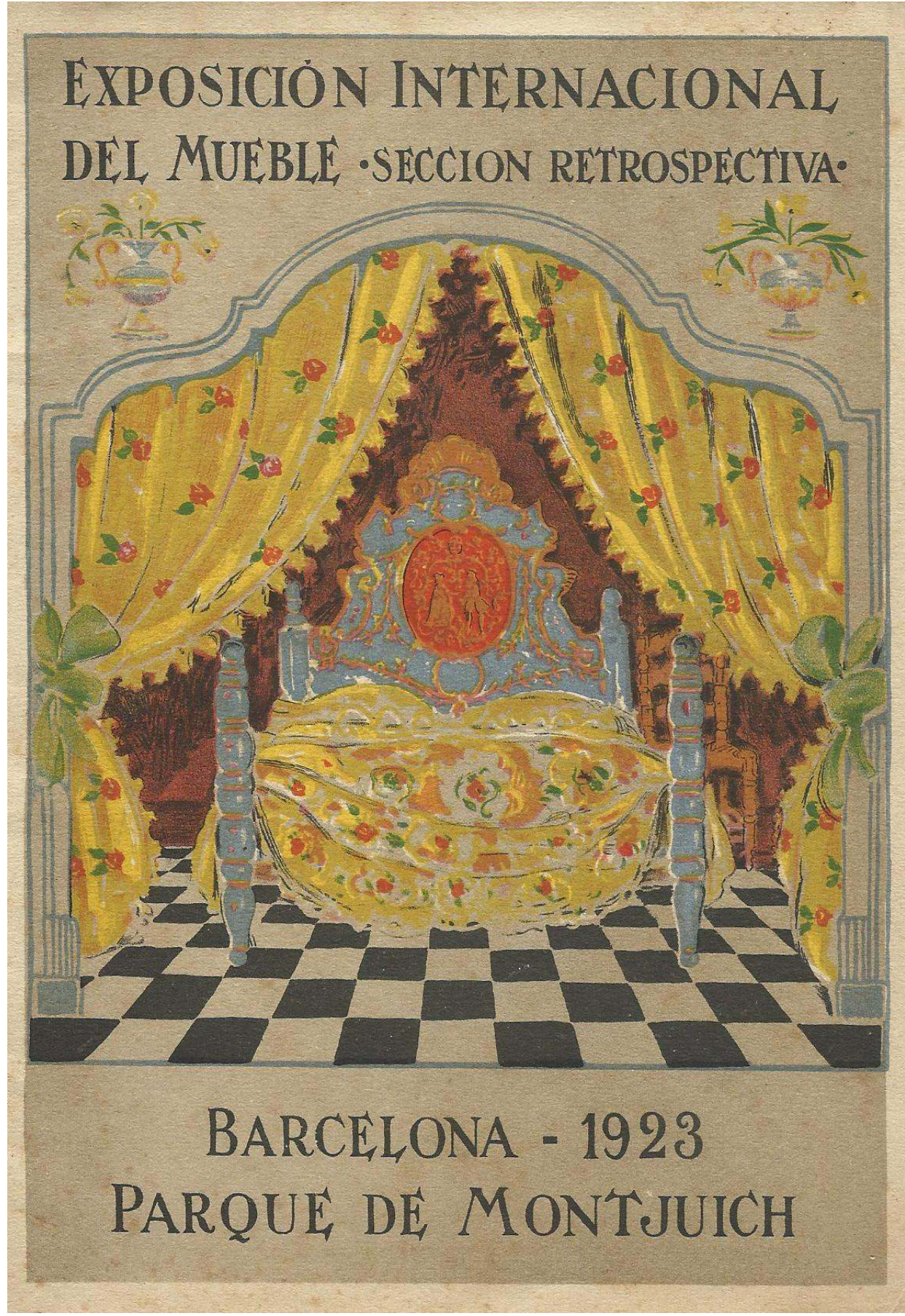

${ }^{19}$ Exposición Internacional del Mueble y Decoración de Interiores. Sección Retrospectiva. Guía del Visitante, Barcelona, A. López Llausás, 1923. 
Para ser más exactos, la Sección Retrospectiva de la Exposición Internacional del Mueble ofrecía hasta ocho "cuadros" escénicos que permitían al visitante discurrir por una secuencia histórica vertebrada tipológica y cronológicamente en virtud de tres criterios clasificatorios: identificación estilística, cronología básica y contextualización histórica en un reinado. La Guía del Visitante apunta también a determinados referentes escenográficos que sirvieron de "inspiración" a las distintas "composiciones". A saber:

\begin{tabular}{|c|c|c|c|}
\hline $\begin{array}{l}\text { Denominación } \\
\text { Sala }\end{array}$ & Cronología & $\begin{array}{l}\text { Referente } \\
\text { histórico- } \\
\text { escenográfico }\end{array}$ & $\begin{array}{l}\text { Contexto } \\
\text { histórico }\end{array}$ \\
\hline Románica catalana & $\begin{array}{l}\text { Último tercio } \\
\text { siglo XIII }\end{array}$ & $\begin{array}{l}\text { Castell Vell } \\
\text { (Solsona) }\end{array}$ & $\begin{array}{l}\text { Pedro III de } \\
\text { Aragón }\end{array}$ \\
\hline Gótica catalana & $\begin{array}{l}\text { Segunda mitad } \\
\text { siglo XV }\end{array}$ & $\begin{array}{l}\text { Casa de la Pía } \\
\text { Almoyna } \\
\text { (Girona) }\end{array}$ & $\begin{array}{l}\text { Alfonso V de } \\
\text { Aragón }\end{array}$ \\
\hline Renacimiento español & Mitad siglo XVI & $\begin{array}{l}\text { Castillo de } \\
\text { Peñaranda de } \\
\text { Duero }\end{array}$ & Carlos V \\
\hline Barroca castellana & Fines siglo XVII & $\begin{array}{l}\text { Sala de la } \\
\text { Panadería. } \\
\text { Ayuntamiento } \\
\text { (Madrid) }\end{array}$ & Carlos II \\
\hline Barroca mallorquina & $\begin{array}{l}\text { Primera mitad } \\
\text { siglo XVIII }\end{array}$ & $\begin{array}{l}\text { Palacio Marqués } \\
\text { de Vivot (Palma } \\
\text { de Mallorca) }\end{array}$ & Felipe V \\
\hline Barcelonesa Carlos IV & $\begin{array}{l}\text { Última década } \\
\text { siglo XVIII }\end{array}$ & Casa (Barcelona) & Carlos IV \\
\hline Barcelonesa neoclásica & $\begin{array}{l}\text { Principios siglo } \\
\text { XIX }\end{array}$ & Casa (Barcelona) & Carlos IV \\
\hline Romántica barcelonesa & 1860 & Casa (Barcelona) & Isabel II \\
\hline
\end{tabular}

Fuente: Guía del Visitante

Queda claro que con tan ambiciosos planteamientos, los promotores de la muestra no se conformaban con una exposición convencional de mobiliario histórico. Más bien convertían la Sección Retrospectiva en el pretexto perfecto para ir más allá y enganchar con el ejercicio historicista de "resucitar" el pasado que, inspirado por la filosofía romántica, vino a constituir uno de los grandes objetivos culturales entre los sectores 
conservadores del siglo XIX y todavía del primer tercio del $\mathrm{XX}^{20}$. No quedan ausentes tampoco de este proceso, los progresivas miradas a lo castizo que, en el panorama de la España de los felices veinte y con la mirada puesta en la Exposición Iberoamericana de Sevilla de 1929, terminaría alumbrando en Andalucía la denominada «Arquitectura del Regionalismo» como plataforma de exaltación de los valores hispánicos a costa de la "rehabilitación" de lo mudéjar, el protorrenacimiento y el barroco.

Así pues, desde el punto de vista escenográfico, constatamos dos tendencias claras en la habilitación de los "escenarios de época" de la Exposición Internacional del Mueble. De una parte, la que informa las cinco salas que abarcan el período Edad Media-Barroco muy sugestionada, a nuestro entender, por los presupuestos vigentes en la Pintura de Historia. De otra, la que caracteriza a las tres salas correspondientes al contexto comprendido entre los reinados de Carlos IV e Isabel II, resuelta en clave más pragmática y "veraz" en cuanto reflejo de interiores reales y en uso cotidiano en el mismo entorno de las casas aristocráticas y burguesas catalanas, con lo cual la tarea de los organizadores más que de "evocación" cabría denominarla, en este caso, de inequívoca y rotunda "traslación".

Invocando el prestigio infalible de referentes arquitectónicos y/o objetuales reconocidos que funcionan subliminalmente a modo de auténticas "citas de autoridad", la habilitación de las salas románica, gótica, renacimiento, barroca castellana (fig.2) y barroca mallorquina conllevaría, en virtud de lo referido, una serie de esfuerzos añadidos a la mera visualización del mobiliario.

${ }^{20}$ MORENO ALONSO, Manuel, Historiografía romántica española: introducción al estudio de la Historia en el siglo XIX, Sevilla, Universidad, 1979. 


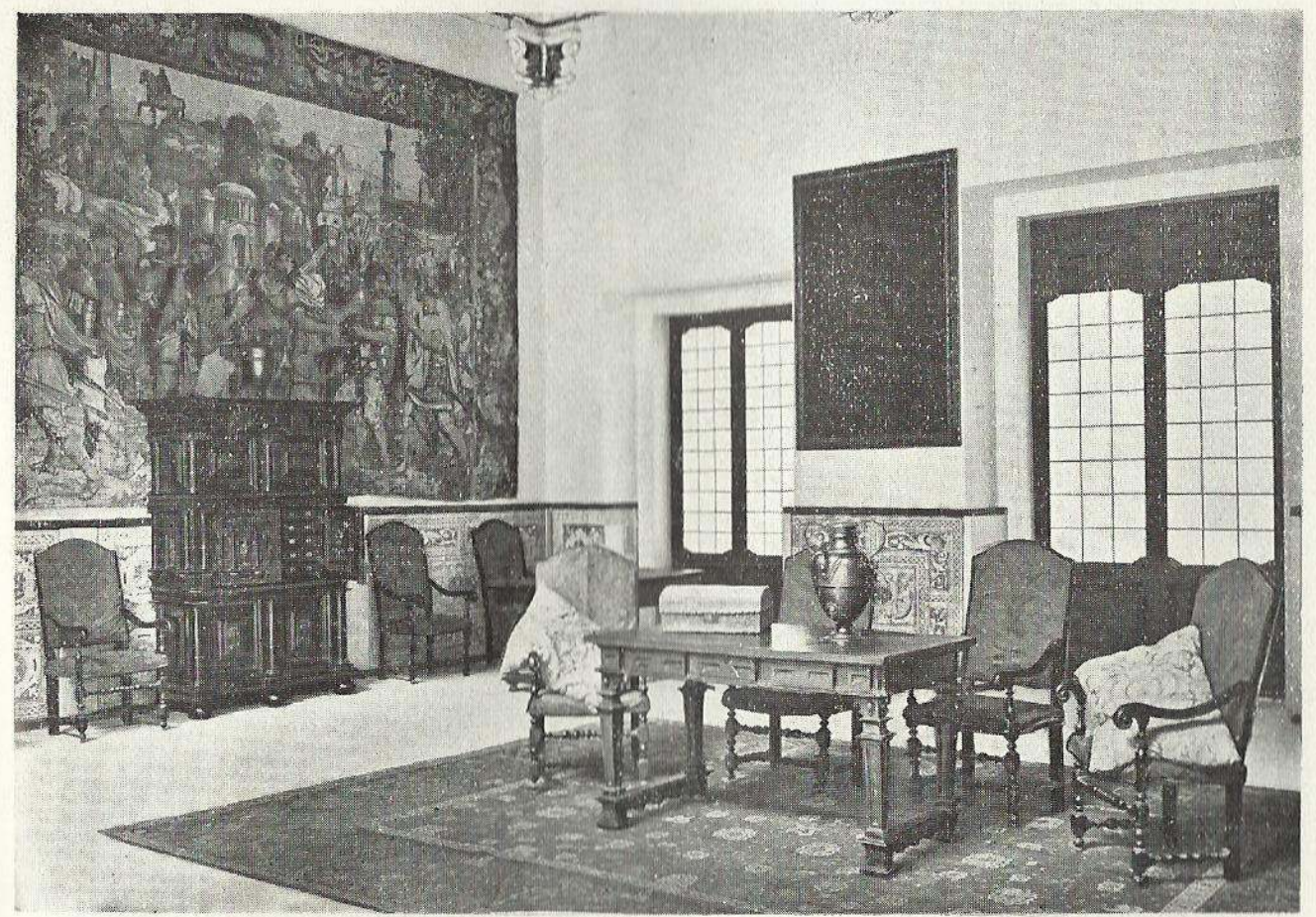

Sala Barroca castellana de fines del diglo XVII, época de Carlos II

Fig. 2. Interior exposicion Barcelona 1923. Sala barroca castellana.

No en balde, en su configuración se impuso un pintoresco "prurito" pseudoarqueologicista que no pretendía otra cosa que hacer experimentar al visitante auténticos "viajes al pasado" en honor a la verdad un tanto imaginativos, potenciando, al mismo tiempo, la puesta en valor de modelos históricos y determinadas épocas presuntamente "recuperables" en pro de la apetecida exaltación nacional. Aplicando a este caso tan singular la argumentación dada en su momento por José Caveda y Nava para uso de los pintores:

La España de la Edad Media, sobre todo, y sus glorias en el siglo XVI, les ofrecen frecuentemente los argumentos que mejor se avienen con sus estudios y en espíritu de que se hallan poseídos, y el gusto y las tendencias de la sociedad a que corresponden y de la cual reciben la vocación y el carácter, el gusto y las inclinaciones ${ }^{21}$.

${ }^{21}$ CAVEDA Y NAVA, José, Memorias para la Historia de la Real Academia de San Fernando y de las Bellas Artes en España: desde el advenimiento al trono de Felipe $V$, hasta nuestros dias, t. I, Madrid, Imprenta de Manuel Tello, 1867, p. 137. 
Contempladas desde esa óptica, las cinco habitaciones "históricas" de la Exposición Internacional del Mueble se convierten en ejercicios de recreación de ambientes románticos similares a los que se detectan entre los ilustradores y escenógrafos cinematográficos, a lo largo de la segunda y especialmente de la tercera década del siglo $\mathrm{XX}^{22}$. Al igual que sucederá en las películas de época, la Exposición Internacional del Mueble parece querer, igualmente, buscar su verosimilitud y pretendido "rigor" en las composiciones pictóricas de Historia, obsesionadas por desarrollar en el lienzo una visualización/documentación del acontecimiento protagonista, resuelta en clave erudita y en función a una pretendida adecuación en imágenes a los principios ideológicos del momento ${ }^{23}$ :

Debe el autor inspirarse en la época y estudiar bien el lugar y la escena; y si es en el campo hasta el clima y la topografía del sitio en que se verificó el hecho; teniendo muy presente las costumbres de las personas y buscando con asiduidad los trajes propios de la época, y en el caso de que no se puedan hallar monumentos o libros que lo digan, debe procurarse conocer las naciones de quienes recibieron sus costumbres, sus leyes, sus armas, sus muebles y su arquitectura, o a quienes tomaron las modas, como lo hicieron los griegos de los egipcios y los romanos de los griegos, a fin de dar todo el colorido y verdad posibles a la representación y causar al espectador una impresión agradable, presentando el suceso tal y como pudo ser, e impresionado su espíritu, de modo que llegue a forjarse la ilusión de que realmente fue así y que pasa a su presencia.

De observar con rigor las reglas expuestas, se consigue no incurrir en anacronismos que desvirtúan y quitan mucha parte del efecto e interés a la obra ${ }^{24}$.

A propósito de lo expuesto y si lo que se pretendía no era sino sancionar "científicamente" la verosimilitud de lo contado, por narración y ambientación, se comprende que los organizadores procurasen armar "convenientemente" el atrezzo de las habitaciones, cuya «parte decorativa será reproducción de los interiores que se conservan, siendo amueblados con objetos auténticos facilitados por los poseedores de los mismos y por la Sociedad de Amigos del Arte de Madrid. El Museo de Barcelona

${ }_{22}$ PÉREZ ROJAS, Javier, ALCAIDE, José Luis, Apropiaciones y recreaciones de la pintura de Historia, in DÍEZ, José Luis, La pintura de Historia del siglo XIX en España, Madrid, Museo del Prado, 1992, pp. 103-118.

${ }^{23}$ SAURET GUERRERO, Teresa, «Metodología de la pintura de Historia: el ejercicio de Moreno Carbonero», in Baetica. Estudios de Arte, Geografía e Historia, 9, 1986, pp. 47-56.

24 MENDOZA, Francisco de, Manual del Pintor de Historia. O sea recopilación de las principales reglas, máximas y preceptos para los que se dedican a esta profesión, Madrid, Imprenta de T. Fortanet, 1870, pp. 32-33. 
hará en esta sección una instalación especial con elementos decorativos propios para la habitación civil»25. En este sentido, si los aposentos de la muestra barcelonesa pretenden articularse y "venderse" al visitante a modo de "cuadros de Historia", no deja de resultar fascinante comprobar el modus operandi con el que pintores como José Uría (El príncipe don Carlos y el Duque de Alba, 1881), Vicente Palmaroli (Una escena musical, 1885), Eduardo Rosales (Presentación de don Juan de Austria a su padre Carlos V en Yuste, 1869) (fig.3) y Miguel Jadraque (Visita del Cardenal Tavera al célebre escultor Alonso Berruguete, 1884), entre otros, se habían enfrentado a la ambientación histórica de los hechos representados recurriendo al mobiliario, en aras de rentabilizar en su pulcra imitación las posibilidades efectistas del cuadro histórico de pequeño formato ${ }^{26}$.

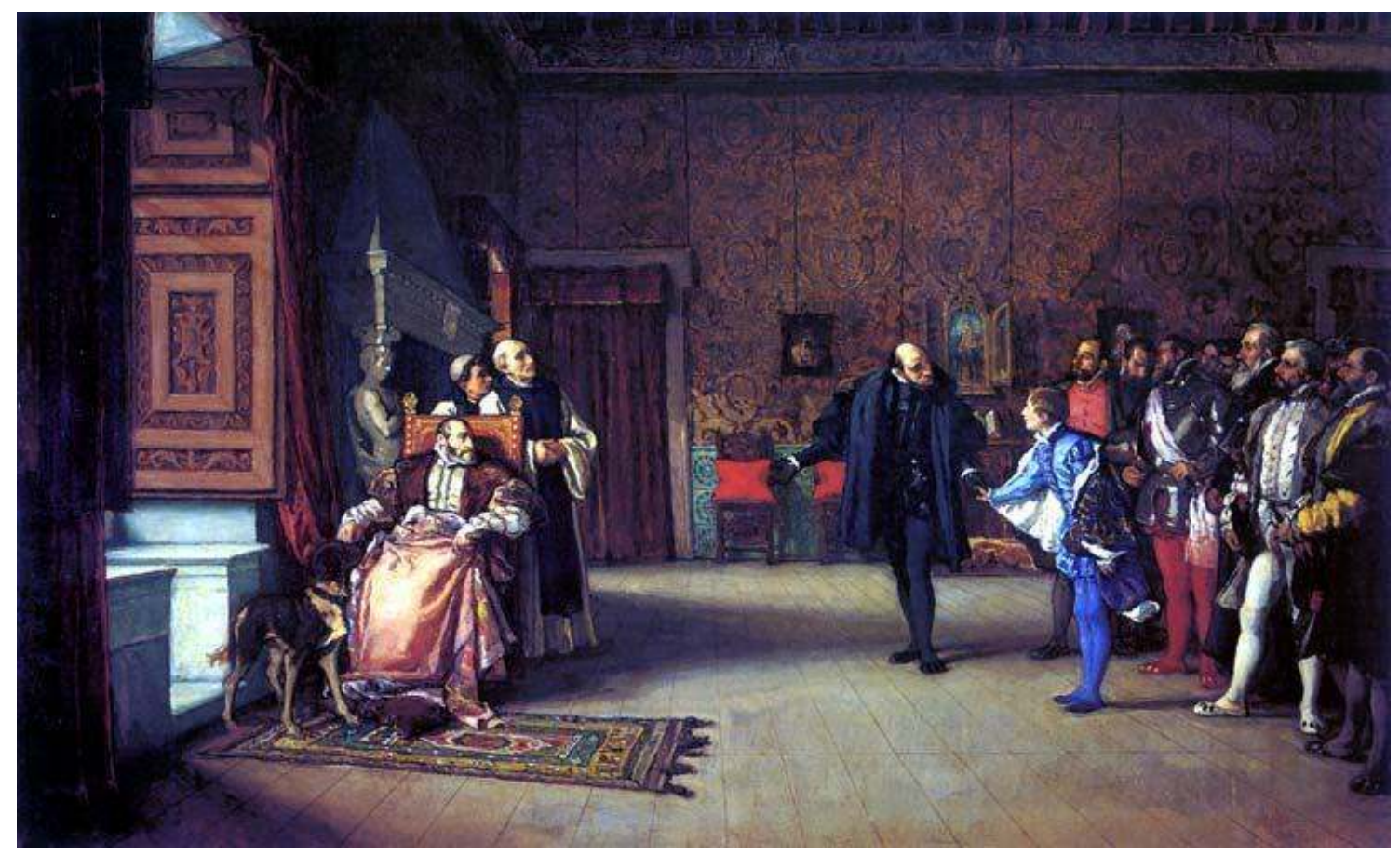

Fig. 3. Eduardo Rosales. Presentación de don Juan de Austria a su padre Carlos V en Yuste. 1869. Museo del Prado.

De hecho, los pintores se dejan seducir por el encanto preciosista inherente a la reproducción minuciosa y acumulativa de muebles y elementos decorativos de época que, bajo su punto de vista, consagran la presunta "fidelidad" cronológica que persiguen, por más que ello suponga aproximar "peligrosamente" sus cuadros históricos al terreno de las escenas historicistas de género. En realidad, los pintores

25 GARRO, Enrique, op. cit.

${ }^{26}$ DÍEZ, José Luis, Evolución de la pintura española de Historia en el siglo XIX, in DÍEZ, José Luis, La pintura de Historia del siglo XIX en España, Madrid, Museo del Prado, 1992, pp. 69101. 
acaban construyendo "habitaciones" tan eclécticas como pudieron serlo posteriormente las de la Exposición Internacional del Mueble. En última instancia, unas y otras hacen gala de un mismo concepto de "decorado" que conlleva la estudiada conjunción de elementos arquitectónicos y objetuales entendidos a modo de "fragmentos" inicialmente dispersos, aunque susceptibles de recomponerse y reubicarse a posteriori para "reconstruir" con ingenio, inteligencia y cierto artificio los períodos históricos evocados, dándose juego con ello a la pretendida glorificación de los valores patrios y a las mitificaciones y mistificaciones que se producen en España en igualdad de condiciones a cualquier otro país.

\section{Crítica y conclusiones}

Para sorpresa de los promotores, las intenciones de "veracidad histórica" pretendidas por la Exposición Internacional del Mueble hicieron aguas ante las encendidas críticas que la muestra suscitó entre determinados sectores de la intelectualidad que quizás no le perdonaron su viraje conceptual hacia el catalanismo españolista en detrimento de la apología nacionalista/secesionista. Especialmente relevante, aunque desde una óptica diferente a la cuestión política, se antoja en la polémica la opinión de Leopoldo Torres Balbás, quien literalmente ponía el grito en el cielo ante lo que juzgaba el diseño inapropiado de unas estancias que «daban escasa idea de lo que ha sido nuestro arte de la decoración doméstica»27. La reacción "académica" no se hizo esperar con la muestra "alternativa" L'amoblement $i$ els atuells de la casa antiga a Catalunya que, auspiciada por la Junta de Museos, tuvo como escenario el Parque de la Ciudadela y que, frente a la puesta en escena de interiores falseados ${ }^{28}$ y los alardes "fantasiosos" de su antagonista, se pretendía fuese «de gran verismo, procurando el mayor rigor científico a la vez que didáctico, al acompañar de documentos escritos y reproducciones fotográficas de composiciones pictóricas antiguas de los objetos presentados ${ }^{29}$.

Llegados a este punto, y pese a la visión de sus detractores, destacamos la importancia de la Sección Retrospectiva de la Exposición Internacional del Mueble y Decoración de Interiores de Barcelona de 1923, como una forma particular de afrontar y vehicular la dinámica habitual en tales muestras. En este sentido, si el museo se

27 TORRES BALBÁS, Leopoldo, «Unas salas de la Exposición Internacional del Mueble y Decoración de Interiores, en Barcelona, en 1923», in Arquitectura: Órgano de la Sociedad Central de Arquitectos, 76, 1925, pp. 189-196.

${ }^{28}$ MOYA VALGAÑÓN, José Gabriel, op. cit., p. 15.

29 Ibidem, p. 20. 
convierte en el "templo" de la cultura donde quedan sujetos a la "canonización" del público los objetos "reverenciados" por su antigüedad, por su valor, por su importancia, por su mérito, por su acabado, por su autor, por su poseedor... en definitiva, por su aura, la exposición adquiere la condición de "feria" que hace las veces de canal de difusión para transacciones de compraventa y descubrimientos y avances científicos y tecnológicos, además de espacio privilegiado para el intercambio cultural y la propaganda nacionalista que pone de manifiesto las proezas de cada país en el contexto universal.

Qué duda cabe que los criterios "pintorescos" y "particulares" de las ocho habitaciones de la Sección Retrospectiva se sitúan en un insólito estadio intermedio entre la musealización y la exposición, al querer investir la celebración de un evento esencialmente "comercial" del sentido poético consustancial a la visión romántica de la Historia. Lo cierto es que la agudeza de los organizadores y el entusiasta colaboracionismo de las instituciones y coleccionistas terminó convirtiéndola en una "feria" pero de otro tipo: la Feria de las Vanidades de quienes gozaban el mueble, poseían el mueble y contemplaban en el mueble un testimonio antropológico vivo de sus luces y sus sombras, de sus logros y sus miserias, de su identidad individual y de su sentimiento nacionalista, en definitiva. 


\section{* Los autores}

Juan Antonio Sánchez López es Doctor en Historia del Arte y Profesor Titular del Departamento de Historia del Arte de la Universidad de Málaga, Premio Extraordinario de Licenciatura y Premio Extraordinario de Doctorado. En su trayectoria profesional desarrolla progresiva y/o simultáneamente cuatro vías de investigación: Historia y temas del Arte de la Edad Moderna, Iconografía, Historia de la Escultura y Creación Mediática y Arte Contemporáneo. Desde 1999 se suma una quinta, orientada hacia la cuestión de los Estudios de Género, Historia e Historia del Arte. Todas ellas se ven oportunamente reflejadas y consolidadas en sus publicaciones y docencia cotidiana en los diferentes ciclos formativos, dirección de Tesis Doctorales, Memorias de Licenciatura, Trabajos fin de Máster y Trabajos tutelados DEA, participación en proyectos, cursos, seminarios y congresos y demás acciones de difusión de los resultados científicos, a nivel nacional e internacional. Actualmente es director y docente del Máster de Escultura Barroca Española, impartido en la Universidad Internacional de Andalucía.

URL: < http://www.studistorici.com/progett/autori/\# SánchezLópez >

Antonio Rafael Fernández Paradas es Doctor en Historia del Arte, Licenciado en Documentación y Perito Tasador en Antigüedades y Obras de Arte. Actualmente, forma parte del claustro de profesores de la Universidad Internacional de Andalucía (UNIA). Ha trabajado en diversas casas de subastas de arte (Durán y Lamas Bolaño). Especialista en Artes Decorativas, sus líneas de investigación versan sobre iconografía religiosa, el círculo de escultores antequeranos, historia e historiografía del mueble español, así como cerámica, marfiles y cuestiones relacionadas con el mercado del arte. Actualmente es director y docente del Máster de Escultura Barroca Española, impartido en la Universidad Internacional de Andalucía

URL: < http://www.studistorici.com/progett/autori/\# FernándezParadas >

\section{Per citare questo articolo:}

SÁNCHEZ LÓPEZ, Juan Antonio, FERNÁNDEZ PARADAS, Antonio Rafael, «Identitades vernáculas, propaganda subliminal y sentimiento nacionalista La "Sección retrospectiva" de la exposición internacional de Barcelona de 1923 o la feria de las vanidades del meuble español», Diacronie. Studi di Storia Contemporanea, 29/09/2014, URL:< http://www.studistorici.com/2014/09/29/sanchez-lopez_fernandez-paradas_numero_19/ >

Diacronie Studi di Storia Contemporanea $\beta$ www.diacronie.it

Risorsa digitale indipendente a carattere storiografico. Uscita trimestrale. redazione.diacronie@hotmail.it

Comitato di redazione: Jacopo Bassi - Luca Bufarale - Elisa Grandi - Deborah Paci - Fausto Pietrancosta - Matteo Tomasoni - Luca Zuccolo Diritti: gli articoli di Diacronie. Studi di Storia Contemporanea sono pubblicati sotto licenza Creative Commons 2.5. Possono essere riprodotti a patto di non modificarne i contenuti e di non usarli per fini commerciali. La citazione di estratti è comunque sempre autorizzata, nei limiti previsti dalla legge. 